\title{
A confidential inquiry into asthma deaths in Wales
}

M L Burr, B H Davies, A Hoare, A Jones, I J Williamson, S K Holgate, R Arthurs,
I G C Hodges
Centre for Applied

Public Health

Medicine, Cardiff, UK

M L Burr

Llandough Hospital,

Penarth, UK

B H Davies

A Hoare

Princess Street

Surgery, Gorseinon,

Swansea, UK

A Jones

Newport Chest Clinic,

Newport, UK

I J Williamson

The Surgery, High

Street, Barry, UK

S K Holgate

R Arthurs

East Glamorgan

Hospital, Church

Village, UK

I G C Hodges

Correspondence to:

Dr M L Burr, Centre for

Applied Public Health

Medicine, University of

Wales College of Medicine,

Temple of Peace and Health,

Cathays Park, Cardiff

CF1 3NW, UK.

Received 26 April 1999

Returned to authors

18 June 1999

Revised manuscript received

12 July 1999

Accepted for publication

22 July 1999

\begin{abstract}
Background-Death from asthma is regarded as preventable in principle, especially under the age of 65 years.

Methods-In 1994 a confidential inquiry was set up to investigate deaths attributable to asthma in residents of Wales under the age of 65 years. During the period of the inquiry 92 cases were notified as being ascribed to asthma, or (in 1996) having a mention of asthma on the death certificate. Of these, 80 were investigated further with the help of general practitioners, hospital notes, and relatives. The details were then considered by a small panel of doctors who endeavoured to identify factors that may have contributed to the deaths.

Results-Asthma was considered to be the underlying cause of 52 deaths. Although disease severity was usually a major factor, some aspect of the patient's behaviour or circumstances seemed to have contributed to 31 deaths, while in 15 cases there was probably a deficiency in medical care.

Conclusions-Some preventable asthma deaths still occur, particularly in relation to inadequate treatment. Factors associated with patients' behaviour and circumstances are more difficult to tackle but, if doctors are aware of high risk patients, increased vigilance may prevent some deaths.

(Thorax 1999;54:985-989)
\end{abstract}

Keywords: asthma; asthma death; Wales

Asthma is not a common cause of death. It accounts for about 140 deaths per annum in Wales (population 2.9 million), most of which are in persons over the age of 65 years. If the disease is correctly treated the risk of death should be extremely low, so that asthma death is regarded as a marker of "avoidable mortality". ${ }^{2}$ Several confidential inquiries have been conducted into asthma deaths, including studies in Cardiff between 1963 and $1974 .^{34}$ In 1979 a confidential inquiry in two regions of England found potentially preventable factors in $86 \%$ of persons aged 15-65 years dying of asthma. ${ }^{5}$ Since that time there have been substantial advances in asthma treatment, including the widespread use of preventive steroid inhalers, so that death from asthma should now be very rare.

In 1991 the National Task Force on Asthma was set up with support from the Department of Health, the National Asthma Campaign, and various physicians. It called for a confidential inquiry into asthma death to be undertaken in certain parts of Britain. The present study relates to the inquiry conducted in Wales, the objectives being twofold-(1) to investigate the degree to which avoidable factors contribute to asthma death and (2) to see whether the picture of avoidable asthma death and its causes have changed since a similar survey was conducted in Cardiff between 1963 and 1974.

\section{Methods}

The inquiry was set up in September 1994 and continued to the end of 1996 . The subjects were residents of Wales under the age of 65 years whose death certificates had been coded to asthma as the "final underlying cause" if this was stated, or otherwise to asthma as the "original underlying cause". Other deaths were also notified in 1996 where the death certificate contained any mention of asthma in Part I or Part II, or had been coded to include the ICD-9 code 493 as one of the multiple causes. Death notifications were obtained initially from Departments of Public Health Medicine throughout Wales and then from the Office for National Statistics. Approval was obtained from local research ethics committees in all parts of Wales. Each patient was allocated a code number and the following procedure was set in motion:

1. The hospital records (if any) were obtained.

2. A letter was sent to the general practitioner (GP) explaining the study and requesting the notes; if they had been returned to the health authority they were requested from there.

3. The GP was contacted by an asthma nurse and asked for an interview at which a questionnaire was completed. An assurance was given that all information would be treated in strict confidence so as not to allow identification of the patient or doctor to anyone outside the immediate study team.

4. Subject to the GP's agreement, a letter was sent to the next of kin explaining the study and inviting participation. Those who agreed were visited by the asthma nurse who completed a confidential questionnaire.

5. If the case had been referred to the coroner, a report of the post mortem findings was requested.

6. The information gathered from these sources was considered by a small panel of physicians comprising a consultant in thoracic medicine, a GP, and a public health 
physician, together with a consultant paediatrician when considering death in childhood. They took a consensus view on the factors contributing to the death according to criteria agreed by a working party of the National Asthma Task Force. The hospital and GP records were then returned and all documents allowing identification of the cases were destroyed so that the patients became completely anonymous from this point.

\section{Results}

The following findings relate to deaths that occurred between 1 September 1994 and 31 December 1996; one death earlier in 1994 was investigated in a pilot phase and is also included. There were 20 deaths notified in 1994, 35 in 1995, and 37 in 1996, 14 of which had not been ascribed to asthma. Of the 92 cases notified, seven were not pursued because the wording of the death certificate suggested strongly that the death was attributable to another major illness, two deaths occurred outside Wales, and three further cases were not investigated because no contacts could be traced, relevant notes could not be found, or litigation was pending. The remaining 80 deaths were investigated further and considered by the panel.

Some information was obtained from the GP for 72 of these cases, including all those that were ultimately considered to be asthma deaths, though it varied in degree of completeness. Some of the GPs had retired or were otherwise not available for interview; some could not remember the details. The GP notes varied greatly in their usefulness for the present purpose. Relatives and carers gave information for only 27 of the patients; other relatives were not contacted because the GP thought it inadvisable, because the relative did not respond to a request, or because there was no suitable relative to approach. Hospital notes were examined for all relevant cases; in 11 cases there was no evidence that the patient had ever attended hospital for asthma. Necropsy reports were obtained when a post mortem examination had been conducted, which had occurred in 53 cases. In two cases the panel considered the hospital notes and coroner's report first and then decided not to proceed further as the death was evidently not attributable to asthma.

In the opinion of the review panel, asthma was not the underlying cause of death in 28 cases (table 1). Of 22 deaths that had been coded to asthma, several appeared to be due to exacerbations of chronic obstructive pulmonary disease; others were attributable to a variety of conditions including pneumonia, left ventricular failure, cor pulmonale, other car-

Table 1 Panel's opinion regarding deaths notified

\begin{tabular}{llcc}
\hline & $\begin{array}{l}\text { Death certificate } \\
\text { coded to asthma }\end{array}$ & $\begin{array}{l}\text { Death certificate not } \\
\text { coded to asthma }\end{array}$ & All cases \\
\hline Investigated: asthma death & 49 & 3 & 52 \\
Investigated: not asthma death & 22 & 6 & 28 \\
Not investigated & 7 & 5 & 12 \\
Totals & 78 & 14 & 92 \\
\hline
\end{tabular}

*1996 only.
Table 2 Age and sex distribution of asthma deaths

\begin{tabular}{lccc}
\hline $\begin{array}{l}\text { Age group } \\
\text { (years) }\end{array}$ & Male & Female & Total \\
\hline $0-14$ & 0 & 2 & 2 \\
$15-44$ & 9 & 5 & 14 \\
$45-64$ & 13 & 23 & 36 \\
All ages & 22 & 30 & 52 \\
\hline
\end{tabular}

diac disease, $\alpha_{1}$-antitrypsin deficiency, liver disease, carcinomatosis, and an alcohol related seizure. The remaining 52 cases were considered to be true asthma deaths including three in 1996 that had been coded to cardiac arrest, respiratory infection, and obesity, respectively. The age and sex distribution of the asthma deaths is shown in table 2 ; mean ages were 45.1 years for men and 48.7 years for women.

Of these 52 deaths, 32 occurred in the patient's home and eight occurred in transit to hospital or immediately on arrival. Three patients suffered cardiorespiratory arrest before reaching hospital and one two hours later but they were resuscitated sufficiently to be maintained on a ventilator in hospital where they died without having recovered consciousness. Of the four other cases who died in hospital, one stayed overnight in a community hospital and died 15 minutes after transfer to a district general hospital, one died three hours after admission, one was ventilated from admission until death seven weeks later, and one contracted bronchopneumonia and died eight days after admission. Four deaths occurred in other locations.

Thirty eight of these patients $(73 \%)$ were currently taking inhaled steroids. In another four cases the GP notes suggested that inhaled steroids were available on repeat prescription but the patient did not appear to have been using them recently. Twenty one patients had been admitted to hospital for asthma on a previous occasion during the past 12 months.

The contributory factors were broadly classified into three groups. Firstly, "disease factors" were those aspects of the disease itself that brought about the death. Since all the patients died of asthma, a disease factor might be considered to apply in every case. In some, however, the death appeared to be largely attributable to aspects of management or behaviour without which the disease would not have been fatal, so the term is used here in a more limited sense. Secondly, there were factors relating to the patient's behaviour, psychosocial conditions or other circumstances. For brevity, these factors were called "patient factors"; it is not intended to imply any attribution of blame by this term. Thirdly, there were aspects of the medical management (in primary or secondary care) that appeared to have contributed to some deaths; these were termed "doctor factors", again without any attribution of blame. The distribution of these factors is shown in table 3. In one case (with disease and patient factors) delay in the arrival of the ambulance may also have contributed to the death.

DISEASE FACTORS

In 17 cases an acute catastrophic attack occurred in patients whose asthma was previ- 
Table 3 Distribution of factors in asthma deaths

\begin{tabular}{lrrr}
\hline & \multicolumn{3}{c}{ Number of deaths } \\
\cline { 2 - 4 } Factor & Males & Females & Total \\
\hline Disease only & 5 & 10 & 15 \\
Patient only & 4 & 1 & 5 \\
Doctor only & 0 & 1 & 1 \\
Disease + patient & 10 & 7 & 17 \\
Disease + doctor & 1 & 4 & 5 \\
Patient + doctor & 1 & 2 & 3 \\
Disease + patient + doctor & 1 & 5 & 6 \\
All disease & 17 & 26 & 43 \\
All patient & 16 & 15 & 31 \\
All doctor & 3 & 12 & 15 \\
Total number & 22 & 30 & 52 \\
\hline
\end{tabular}

ously mild or moderate; one of these was an acute allergic reaction to nuts. In seven patients the chronic severe disease seemed to be the more important factor, while in another 19 cases acute and chronic elements were prominent, a sudden deterioration occurring in a patient whose asthma was already severe. Four patients had co-existing physical conditions that aggravated their asthma: bronchiectasis, obesity, severe kyphoscoliosis, and bronchopneumonia.

\section{PATIENT FACTORS}

The factors relating to the patients themselves were the most complex and occurred in a slightly higher proportion of male than female patients. The following factors were considered to have possibly contributed to the death or to be related to it: failure to keep appointments (13 cases), depression and other psychiatric conditions (10), poor compliance with treatment (9), alcohol or drug abuse (5), denial of illness severity (4), smoking (4), social problems (3), recent bereavement (2), refusal of hospital admission (2), mental handicap (1), irresponsible behaviour (1), and "death wish" (1). Among 39 cases in whom details of the final attack were known, six patients (or their carers) delayed seeking medical help. In most cases more than one of these factors was present. Thirteen patients were living alone.

\section{DOCTOR FACTORS}

There were 15 deaths in which a "doctor factor" was probably present. The commonest failure in medical care was inadequate treatment in view of the known severity of the disease. This was adjudged to have occurred in eight cases for whom inhaled steroids had not been prescribed recently, if at all. In four cases it was felt that the arrangements for follow up were inadequate. Four patients had been prescribed drugs that may have had an adverse effect on their asthma, one of them after admission to hospital. These comprised $\beta$ blockers, non-steroidal anti-inflammatory preparations, and a combination of intravenous diazepam and diamorphine given to a patient with anoxic convulsions. Non-admission to hospital (two cases), failure of diagnosis (one case), and the absence of shared care (one case) were also considered to be relevant factors. More than one of these factors operated in some instances.

In addition to the above, in some cases it was thought that the lack of domiciliary oxygen may have been a preventable factor. Another possible contributory factor was the absence of a written management plan.

\section{Discussion}

The cause of death as entered on the death certificate is frequently unreliable as an indication of asthma death. In many of the cases reviewed it was felt that the death was actually attributable to another condition, as other investigators have found. ${ }^{6-8}$ It is also recognised that deaths may be really attributable to asthma but coded to other diseases owing to the way the death certificate has been completed. ${ }^{68}{ }^{9}$ In order to detect such cases, deaths with any mention of asthma on the certificate were investigated in 1996 and three false negatives were discovered.

In comparing these findings with those of the early Cardiff studies, the most obvious difference is the relative rarity of death in hospital in the more recent study. In 1963-74 there were 90 deaths outside hospital ${ }^{3}$ and 53 in hospital, only five of which occurred within two hours of arrival. ${ }^{4}$ In the present series there were only two deaths in hospital (including the transferred patient) apart from those who were moribund on arrival, some of whom were maintained on a ventilator without ever regaining consciousness; there were no cases comparable to the 21 patients in 1963-74 who died in hospital despite a good initial clinical response. ${ }^{4}$ The 1963-74 studies covered a wider age range but mean ages in the combined series were very similar ( 45.3 years for men, 51.7 years for women) to those in the present study (45.1 and 48.7 years, respectively). The trend away from hospital death was already apparent in the West Midlands and Mersey areas in $1979^{5}$; more recent studies in East Anglia also found very few asthma deaths in hospital wards. ${ }^{10} 11$ It is clear that the further reduction of asthma mortality must be directed to patients in the community and the way their treatment is managed.

The details of these deaths are broadly similar to those that have been previously reported. The typical rapidity of the final attack has often been noted ${ }^{3510}$ though it tends to occur in patients who already have severe disease..$^{3-5} 7$ In the current study $40 \%$ of patients had been admitted to hospital for asthma on a previous occasion during the past year, the same percentage as in the combined series of inpatients and outpatients in Cardiff in 1963-74. ${ }^{34}$ All studies agree that preventable factors can frequently be identified, although it is difficult to assess how easily a death could have been prevented. In an inquiry of this kind the information available is inevitably limited, sometimes to an unsatisfactory degree, so that the panel's opinion is only an assessment of the balance of probabilities.

Not surprisingly, the major contributory factor in asthma death is the disease itself. Half the patients already had severe disease; in most of these a sudden acute episode was superimposed on their chronic condition. Only in a few did a final catastrophic attack occur against a background of mild or moderate asthma. It is 
clear that both patients and doctors need to be aware of the importance of ensuring that severe asthma is carefully managed in view of the danger of a fatal outcome.

Factors involving the patient's behaviour and circumstances were identified in more than half the asthma deaths, and tended to occur more among men than among women. In the absence of a control group it cannot be known with certainty to what extent they are associated with fatal as distinct from non-fatal asthma, but the balance of probabilities suggested that they contributed to the death. These factors seemed to be particularly complex and intractable. Psychiatric illness, failure to keep appointments or comply with treatment, symptom denial, alcohol or drug abuse, and social problems (including bereavement) were frequently noted, as others have found. ${ }^{10-13}$ These factors are not all under the patients' control; even the failed appointments may sometimes reflect deficiencies in the perceived quality of care at the hospital or general practice. There was a significant delay in summoning medical help in $15 \%$ of cases whose details were known, compared with $23 \%$ in the earlier Cardiff study of deaths occurring out of hospital. ${ }^{3}$ It is difficult to see how all these deaths could have been prevented by medical means alone. Nevertheless it is possible that, if doctors are alerted to a greater risk of death among such patients, a higher degree of surveillance or mobilisation of other resources might avert death in some cases.

Both undertreatment and overtreatment have been suspected of contributing to some asthma deaths. ${ }^{14}$ The underuse of corticosteroids was noted in the early Cardiff studies. ${ }^{34}$ In the present study no deaths were attributed to overtreatment, but undertreatment appeared to be a factor in some cases, particularly in terms of preventive therapy (inhaled or oral corticosteroids). In a few cases the doctor did not seem to have followed up the patient appropriately, given the known severity of the patient's disease. In two cases $(4 \%)$ the GP failed to admit the patient to hospital, compared with $6 \%$ in the combined Cardiff series during 1963-74. Four patients had received drugs that are contraindicated in the presence of asthma, partly through failure to diagnose the disease. In only one case was ambulance delay noted.

In $70 \%$ of the asthma deaths factors were identified relating to patients, doctors, or both, apart from the severity of the disease itself. It must be acknowledged that in all these cases it is difficult to assess the degree of preventability; misleading conclusions can easily be drawn when circumstances are imperfectly known and reviewed with hindsight after a fatal outcome. Nevertheless, these findings have some practical implications. If fatalities are to be reduced, attention should be paid to the continuing education of doctors as well as patients. Severe chronic disease and the presence of adverse psychosocial factors must be recognised as calling for particular vigilance so that patients at high risk can be identified and offered appropriate management. It is likely that the fatal cases represent the tip of an iceberg of suboptimal asthma management; in an Australian study patients who suffered near-fatal attacks of asthma resembled fatal cases in respect of quality of management, psychiatric profiles, and other relevant matters. ${ }^{15}$ Thus, improvements designed to reduce asthma mortality would probably have an even bigger effect on asthma admissions and morbidity. It cannot be assumed, however, that these findings apply to persons over 65 years of age when most asthma deaths occur and when co-morbidity is likely to play a greater part. ${ }^{14}$

In conclusion, the following points should be noted:

- Death certificate coding is an unreliable guide to asthma death.

- Nearly all asthma deaths in persons under 65 years of age occur outside hospital, except for patients who are already moribund on arrival, in contrast to the situation 20-30 years ago.

- In half the cases the disease is chronic and severe; an acute catastrophic attack occurs in a third of patients whose disease is moderate or mild.

- Factors other than the severity of the disease were identified in $70 \%$ of these asthma deaths.

- In $60 \%$ of cases there was a "patient factor", particularly relating to psychosocial problems and poor compliance with treatment. Awareness of such factors should alert the patients' doctors to be especially vigilant.

- In $30 \%$ of cases some aspect of the medical care may have contributed to the death, particularly lack of inhaled steroids, inadequate follow up, or contraindicated medication.

- There is still scope for reducing asthma mortality and, presumably, asthma morbidity also.

We are grateful to Blodwen Davies and Patricia Breay for obtaining some of the information, and to the Welsh Office and the National Asthma Campaign for grants to carry out this enquiry.

1 Charlton J, Lakhani A, Aristidou M. How have 'avoidable death' indices for England and Wales changed? 1974-78
compared with 1979-83. Community Med 1986;8:304-14. compared with 1979-83. Community Med 1986;8:304-14.
Westerling R. Trends in "avoidable" mortality in Sweden, Westerling R. Trends in "avoidable" mortality in Sweden, 1974-1985. F Epidemiol Community Health 1992;46:489-

3 Macdonald JB, Seaton A, Williams DA. Asthma deaths in Cardiff 1963-74: 90 deaths outside hospital. BMF 1976;1; 1493-5.

4 Macdonald JB, Macdonald ET, Seaton A, et al. Asthma deaths in Cardiff 1963-74: 53 deaths in hospital. BMF 1976;2:721-3.

5 British Thoracic Association. Death from asthma in two regions of England. BMF 1982;285:1251-5.

6 Subcommittee of the BTA Research Committee. Accuracy of death certificates in bronchial asthma: accuracy of certification procedures during the confidential enquiry by the fication procedures during the confidential enquiry by

British Thoracic Association. Thorax 1984;39:505-9.
Model D. Preventable factors and death certification in Model D. Preventable factors and death certific
death due to asthma. Respir Med 1995;89:21-5.

8 Smyth ET, Wright SC, Evans AE, et al. Death from airway obstruction: accuracy of certification in Northern Ireland Thorax 1996;51:293-7.

9 Guite HF, Burney PGJ. Accuracy of recording of deaths from asthma: the false negative rate. Thorax 1996;51:924-

10 Wareham NJ, Harrison BDW, Jenkins PF, et al. A district confidential enquiry into deaths due to asthma. Thorax 1993;48:1117-20.

11 Mohan G, Harrison BDW, Badminton RM, et al. A confidential enquiry into deaths caused by asthma in an English health region: implications for general practice. $\mathrm{Br}$ 7 Gen Pract 1996;46:529-32.

12 Strunk RC, Mrazek DA, Wolfson Fuhrmann GS, et al. Physiologic and psychological characteristics associated 
with deaths due to asthma in childhood: a case-controlled study. FAMA 1985;254:1193-8.

13 Joseph KS, Blais L, Ernst P, et al. Increased morbidity and mortality related to asthma among asthmatic patients who use major tranquillisers. BMF 1996;312: $79-83$.
14 Burney P, Ingram R, eds. Asthma mortality: summary of a round-table discussion, New York, January 1997. Eur Respir F 1999;13:221-4.

15 Campbell DA, McLennan G, Coates JR, et al. A comparison of asthma deaths and near-fatal asthma attacks in South Australia. Eur Respir f 1994;7:490-7. 